Article

\title{
The V in VGI: Citizens or Civic Data Sources
}

\author{
Suthee Sangiambut * and Renee Sieber \\ Department of Geography, McGill University, Montreal, H3A 0B9, Canada; E-Mails: \\ suthee.sangiambut@mail.mcgill.ca (S.S.), renee.sieber@mcgill.ca (R.S.) \\ * Corresponding author
}

Submitted: 13 April 2016 | Accepted: 17 June 2016 | Published: 12 July 2016

\begin{abstract}
Volunteered geographic information (VGI), delivered via mobile and web apps, offers new potentials for civic engagement. If framed in the context of open, transparent and accountable governance then presumably VGI should advance dialogue and consultation between citizen and government. If governments perceive citizens as consumers of services then arguably such democratic intent elide when municipalities use VGI. Our empirical research shows how assumptions embedded in VGI drive the interaction between citizens and government. We created a typology that operationalises VGI as a potential act of citizenship and an instance of consumption. We then selected civic apps from Canadian cities that appeared to invoke these VGI types. We conducted interviews with developers of the apps; they were from government, private sector, and civil society. Results from qualitative semi-structured interviews indicate a blurring of consumer and citizen-centric orientations among respondents, which depended on motivations for data use, engagement and communication objectives, and sector of the respondent. Citizen engagement, an analogue for citizenship, was interpreted multiple ways. Overall, we found that government and developers may increase choice by creating consumer-friendly apps but this does not ensure VGI offers an act of civic participation. The burden is placed on the contributor to make it so. Apps and VGI could potentially further a data-driven and neoliberal government. Planners should be mindful of the dominance of a consumer-centric view even as they assume VGI invariably improves democratic participation.
\end{abstract}

\section{Keywords}

Canada; citizen engagement; consumer; democracy; governance; government; municipal; open data; participation; volunteer

\section{Issue}

This article is part of the issue "Volunteered Geographic Information and the City", edited by Andrew Hudson-Smith (University College London, UK), Choon-Piew Pow (National University of Singapore, Singapore), Jin-Kyu Jung (University of Washington, USA) and Wen Lin (Newcastle University, UK).

(C) 2016 by the authors; licensee Cogitatio (Lisbon, Portugal). This article is licensed under a Creative Commons Attribution 4.0 International License (CC BY).

\section{Introduction}

Cities across North America and Europe are collecting Volunteered Geographic Information (VGI) via mobile and browser-based apps. Their hope is that VGI can lead to better decision-making, improve service delivery, and empower municipal residents to become more involved in governance (Mooney, Sun, \& Yan, 2011). Goodchild describes VGI as the "widespread engagement of large numbers of private citizens, often with little formal qualifications in the creation of geographic information" (Goodchild, 2007a, p. 212). Goodchild and others (e.g., Ganapati, 2011) perceive VGI's potential to engage a large body of the public at low costs to entry for capital and expertise, for example offering a mechanism for government to complete existing spatial data infrastructures. Authors argue that VGI in governance fundamentally shifts the relationship between the citizen and the state, in part because VGI challenges the notion of authoritative data (Coleman, 2013). In this formulation, the contributor becomes an essential component of new incarnations of the city, like the 
smart city, because their VGI is crucial to a dynamic location awareness of the urban environment (Roche \& Rajabifard, 2012).

Review of VGI literature points to a dearth of the government perspective, particularly local government, on VGI. Extant discourse related to government emphasises spatial data accuracy, completeness of coverage, contributor motivations, and to a lesser extent, digital inequities revealed in the contributions (Coleman et al., 2009; Haklay 2010; Minkoff 2016). Because of this focus, governments may resist adopting VGI if it cannot be adapted to existing data structures and workflows or if the data is viewed as untrustworthy (Haklay, Antoniou, Basiouka, Soden, \& Mooney 2014). Three areas are needed for VGI incorporation into government decision making: formalisation of VGI collection, collaboration within and between governments, and a reframing of citizens as partners in the planning process (Johnson \& Sieber, 2011, 2013). As the focus is frequently more on the ' $\mathrm{V}$ ' in the acronym than the ' $\mathrm{Gl}$ ', we are interested in how citizens are being formulated in governance.

Our empirical research shows that a specific set of assumptions about the $\mathrm{V}$ in VGI drives the interaction between individuals and their government. We are explicitly interested in the tensions between volunteer as citizen actively engaged in a participatory democracy and volunteer as market-based consumer of government services. VGI is frequently promoted by extolling its democratic potential, with words like empowerment, although empowerment can describe a collective redistributive form of political power or an individual emancipation from inefficiency. To examine this tension, we look at expressions of the V in VGI through the lens of civic applications or "apps". Unlike other research that repurposes VGI for uses other than the original intent of the contributor (e.g., in OpenStreetMap or Twitter), we look at active contributions, where contributors and app developers possess an explicit sense of how the data will be used.

This paper explores the citizen-consumer dichotomy and its expression in government and developer perceptions of VGI contributors. We first review the literature of VGI and related fields, highlighting invocations of the volunteer. We present a typology that operationalises VGI in city governance as an act of citizenship and as an instance of consumption. We then select civic apps that best represent these VGI types. We also chose to investigate a hybrid app, an app that ostensibly expresses volunteer as both citizen and consumer in case the dichotomy fails to neatly divide. We present the results of qualitative semi-structured interviews conducted with developers of these apps, who come from government, private sector, and civil society organisations. Findings from interviews indicate a level of citizen-centric perception in all apps, which sometimes conflicted with a consumer-centric orientation. Our hope in this research is that planners and civic app developers are mindful of the dominance of certain frames. Government may assume VGI invariably improves democratic participation even as its app casts the individual as a neoliberal consumer.

\section{Literature Review}

Numerous themes, like spatial data accuracy and volunteer motivations, connect VGI to governance because of VGI's potential to shift the roles and responsibilities of government relative to its inhabitants and VGI's opportunities to broaden public participation. We review the ways in which the VGI and related literatures have characterized the volunteer and the way this characterization propels thinking about governance in the Web 2.0 era.

Arguably, the largest discursive element of the volunteer in VGI invokes the volunteer as a democratic actor. Adams (2013, p. 465), for example, believes that "VGI might facilitate new forms of activism, participatory democracy and neighbourhood empowerment". Elwood (2008) suggests that the heterogeneity of VGI platforms may enable new narratives that circumvent existing data and power structures. Seeger (2008) describes VGI's potential to address low rates of public participation. VGI is argued to have a democratising effect over data production and use, offering a "social transformation in the way data can be collected and shared" (Fast \& Rinner, 2014, p. 1287). Whereas information technologies can be used to promote participation, VGI contributors also have the power to undermine participatory processes (intentionally or unintentionally), for example overloading the process with information targeted towards a specific agenda (Tulloch, 2008). Some VGI, such as that passively harvested from social networks, may not even be intended as part of a political process. Similar to Public Participation GIS (PPGIS), VGI's predecessor, participants may be simultaneously marginalised and empowered in VGI (Harris \& Weiner, 1998). A user interface may dissuade a broader public from participating, while being quite accessible to the technologically-comfortable.

The word 'citizen' is regularly invoked in VGI, alongside collective agency, empowerment, democracy and public participation, although citizen is usually undefined or used synonymously with individual or volunteer. Goodchild (2007a, 2007b) describes the V in VGI as intelligent citizens sensors who can outperform credentialled experts in identifying subtle changes in their environment. A related concept from government is citizen-sourcing, defined as the intersection of engagement, crowdsourcing, and open government to leverage the knowledge of individuals (Nam, 2012). Nam links empowerment to citizen sourcing, which "may change the government's perspective on the public from an understanding of citizens as 'users and 
choosers' of government programs and services to 'makers and shapers' of policies and decisions" (Nam, 2012, p. 13). What complicates the $V$ as citizen is that VGI is envisaged as an individual activity (Sieber \& Haklay, 2015), where individuation serves as a precondition for a neoliberal view of the urban resident (Harvey, 2005; Massey, 2013). Here the V in VGI trades collective participatory engagement found in PPGIS for individuated consumptive behaviour in a market-based relationship with the state. Needing a working definition, we stipulate the citizen, albeit individuated, as one who engages with government on political issues for a collective good.

Citizen sensing and sourcing shift citizenship towards third wave styles of governance like New Public Management (NPM), where VGI is viewed as a process of coproduction. NPM presents government no longer as a provider of public services but as a manager of service providers, that also promotes outsourcing and market-based decision-making (Denhardt \& Denhardt, 2000; Hood, 1995). In this model, volunteers "play an active role in producing public goods and services of consequence to them" (Ostrom, 1996, p. 1073). Coproduction "extend(s) across the full value chain of service planning...delivering, monitoring, and evaluation activities" (Bovaird, 2007, p. 847).

Coproduction preceded Web 2.0 but is reinvigorated by VGI, through the fusion of users and contributors of content. Termed produsage (Bruns, 2008), this describes a structural shift in economic production, a "collapse of older, production and product-based models" (Bruns, 2007, p. 7). Bruns identifies characteristics of produsage such as community-based production, fluidity in roles, continual development and common property. Bruns thus grounds his characteristics in an economic framing. Budhathoki, Bruce and NedovicBudic (2008) applies the concept of the produser to geographic information, differentiating contributors according to their motivations to contribute and level of expertise. Coleman et al. (2009) apply Bruns's produser to describe contributor motivations from civic and economic perspectives as well as the overlap in these two perspectives. For the purposes of this paper, we define consumers as market-based individuals who view the state as the provider of services and may be coproducers to ensure that efficient targeting of services serve their self-interests.

Forms of governance like NPM act as a paradigm shift that stresses efficiency, customer satisfaction, and profit-seeking behaviour as opposed to democratic empowerment, collective interest, and equity (Aberbach \& Christensen, 2005). In this neoliberal shift VGI allows government responsibilities to be outsourced to volunteers who become part of a service provision ecosystem. Thus a citizen moves toward the market of self-interest, emphasising:
"The liberal definition of the citizen, one that focuses on individual preferences and rights...it deemphasizes...the republican or collective tradition that emphasizes common goods and collective action through political parties, neighbourhood groups and participation in community activities." (Aberbach \& Christensen, 2005, p. 241)

Leszczynski (2012) describes VGI as an enabler of that shift, part of a wave in geospatial web technologies leading to reduced and outsourced government mapping. Outsourcing data collection (and responsibility) transforms the state's role, allowing "corporations, non-state actors, and private citizens...fulfilling functions that were long the exclusive preserve of state mapping organizations" (Leszczynski, 2012, p. 78). Arguments for increasing efficiency or constraining government spending play key roles. The US government now relies on citizens to maintain certain datasets, from location of invasive species, to crisis information, to the underlying road infrastructure (Coleman, 2013; Goodchild, 2007b; Goodchild \& Glennon, 2010). Ghose (2005, pp. 63-64) notes that neoliberalism via technocratically-enabled practices, which include VGI, leads to a multiscalar rescripting of citizenship practices where citizens bear the burden "to be entrepreneurial and to develop the capacity to be an active agent in claiming their urban space".

Why is it problematic to label a volunteer a consumer? When people are liberated from regulations (a goal of neoliberalism), certain people become freer than others and the state dismantles distributive and more equitable policies, focusing instead on decisions that favour specific sectors and individuals (Harvey, 2005; Massey, 2013). The potential is manifest in VGI: if one is not positioned (e.g., in terms of skills or structural bias) to be entrepreneurial, service is not given. Social inequalities such as gender biases and ruralurban divides have been identified in VGI production (Hecht \& Stephens, 2014; Stephens, 2013). A census tract-based analysis of New York City's Open 311 system finds that higher home ownership is correlated with higher reporting; at the same time these areas are likely less subject to graffiti/noise (Minkoff, 2016).

It is easy to dichotomise the roles of the volunteer as either democratic (citizen) or market-based (consumer/producer). While critical of NPM, Aberbach and Christensen (2005) maintain that empowerment exists in both citizen and consumer orientations. A consumer orientation is not automatically disempowering if the democratic context follows the liberal definition of the citizen and is viewed as a more direct form of democracy (Aberbach \& Christensen, 2005). Market based approaches like citizen-sourcing can lead to civic learning by increasing citizens' knowledge of political issues, reducing alienation from decision-making, and minimizing conflicts with government (Nam, 2012). Citizen- 
sourcing may "tap into the unique skills...and knowledge among the public" where citizens provide information, feedback and intelligence (Nam, 2012, p. 449). We speculate that context, such as a liberal tradition of governance, is important in setting how volunteers are perceived and VGI is valued.

Apps and platforms structure data collection and consequently shape volunteer engagement with government. All VGI is structured in some way. In the private sector, Twitter limits each contribution to 140 characters. In the public sector, service requests are increasingly standardised via platforms like FixMyStreet and application program interfaces like Open311. The design and interoperability of software exert significant impacts on how we communicate with cities (Sieber, Robinson, Johnson, \& Corbett, 2016). Governments arguably are shaped by the apps they use to interface with citizens.

Aberbach and Christensen's (2005) concerns are evinced in service request apps. King and Brown (2007) describe FixMyStreet as empowerment, "raising the volume of the citizen's voice", and part of "a growing movement towards encouraging customers/citizens/ patients etc. to take greater control and responsibility for their own well-being" (King \& Brown, 2007, p. 78). Baykurt (2012, p. 11) counters King and Brown's optimism; she contends apps like FixMyStreet may improve efficiency, transparency and accountability of service requests but "simultaneously produces an individualized, momentary, issue-focused government-citizen relationship while neglecting collective action and community power". The conflation of terms like citizen and consumer, or coproduction and empowerment, demonstrates that conflicting views within existing VGI projects need to be closely examined.

\section{Methods}

To assess the citizen-consumer dichotomy in VGIdriven civic apps, we surveyed government and developer perceptions of VGI contributors. A scan for cases in Canada was conducted using criteria from a model we created of the citizen and consumer. Respondents were identified using a two-staged snowball sample. After selection, we solicited government and developer perceptions using qualitative semi-structured interviewing. We then conducted descriptive coding to reveal themes in responses. Questions covered the use of VGI and perceptions about the user and volunteer engagement.

\section{Modelling and Operationalizing the Citizen and the Consumer}

As suggested above, concepts of citizen and consumer overlap and are diluted in ways that complicate operationalisation. We developed a basic model of the citizen and the consumer, which we used to operationalise the two concepts and assist in the selection of cases. We inferred the orientation of the volunteer from developer characterizations of the app as citizencentric or consumer-centric, based on the assumption that developers' characterizations shape app construction and structure the ways that volunteers can contribute. Table 1 shows the four characteristics by which we operationalise citizen and consumer: content, purpose, users, and directionality of communication. Content and purpose serve as the main differentiators between types. For example, an app collecting feedback on public policy to inform said policy would appear to be citizen-centric; an app collecting data that would enhance a public service would appear as consumercentric. The directionality of communication and users of data further resolve unclear cases.

If government views volunteers as citizens then government presumes its residents have expectations of government duties beyond service delivery, such as equitable service coverage. We presume that citizens require demonstrable forms of engagement and aspire to collective needs. Conversely, consumers present government with individual self-interests. With sufficient contributions, VGI represents the aggregation of individual preferences, akin to market demand. In this view, government responds to market forces to deliver public services with efficiency, effectiveness, and customer satisfaction.

Table 1. Volunteers operationalised in apps.

\begin{tabular}{lll}
\hline Criteria & Consumer-centric & Citizen-centric \\
\hline Content & Service delivery, crowdsourcing & Politics, elections, policy, citizen opinions \\
\hline Type of Volunteers & Individuated & Collective \\
\hline Purpose & $\begin{array}{l}\text { Improve services, input into } \\
\text { analysis/decision-making }\end{array}$ & $\begin{array}{l}\text { Collect feedback on policy. Promote } \\
\text { transparency, openness. Advance rights }\end{array}$ \\
\hline End User & Unelected officials & Elected officials \\
\hline Communication & No dialogue. Solely a data-collector & Dialogue possible \\
\hline
\end{tabular}




\subsection{Scan of Apps}

We scanned existing civic apps in five of Canada's major cities: Ottawa, Toronto, Vancouver, Edmonton and Montreal. The first four cities are originators of Canada's open data consortium (Carl, 2012, May 7) so are likely to have mature apps built on their open data platforms. Montreal was added to provide a pool of Francophone apps. Examples of ideal citizen-centric or consumercentric types were selected according to the criteria in Table 1. Our result set, particularly for citizen-centric apps, was small. A recent study found very few examples of apps that promote citizen engagement as opposed to apps that handle service requests (Sandoval-Almazan, Gil-Garcia, Luna-Reyes, Luna, \& Rojas-Romero, 2012).

We were interested the suitability of the citizenconsumer dichotomy for each app and respondent perceptions aligning with the apps' pre-selected category. Not all criteria were required to determine category assignment. Preselection criteria included the content and the end user of the VGI. If according to the app's description and preliminary usage, the content elicited opinion on how government was run then this was deemed citizen-centric. VGI that appeared to be used as simple inputs to government decision-making was viewed as coproductive and thus consumercentric. Requests for services (e.g., 311) were deemed consumer-centric, although we found citizen and consumer categorisation was not easily distinguishable without interviewing respondents. The communication and individual/collective criteria were less important, as we felt it would be difficult to identify apps as citizen engagement and customer feedback prior to interviewing respondents. All app development was outsourced. Outsourcing arrangements reflect the trend in government appification (Sandoval-Almazan et. al., 2012).

A case study $-a$ brief description of its functions and applicable end users-was created for each of the final three apps (Table 2). Citizen Budget, a government budget feedback app, was chosen as the citizen- centric app because it elicits feedback on public policy. Toronto Cycling App, a cycling route app, was chosen as the consumer-centric app due to its crowdsourcinglike functionality, where data is used as input to improve service delivery. VanConnect, a 311 service request app, was chosen because it appeared simultaneously consumer-centric, due to service requests as the VGI content, and citizen-centric, because its feedback mechanism suggested a more engaged form of participation beyond customer feedback. Gordon and Baldwin-Philippi (2013) differentiate types of engagement afforded by Customer (or Citizen) Relationship Management (CRM) systems, ranging from simple one-way transactions (weak engagement), to community-wide interaction that builds community networks (strong engagement). This suggests a hybrid; for example, there may be more to service request apps than just one-way interaction or customer feedback.

\section{Interviews}

Empirical research consisted of qualitative semistructured interviews, where respondents were identified via a two-staged snowball sample. After identifying apps, officials and developers responsible for app development and use were identified. Except for Citizen Budget, municipal officials were contacted and interviewed first. Those interviewed in the first stage referred us to the next respondents in the developer or government side. Questions differed slightly whether we interviewed individuals within government or outside government (outsourced developers). Developers were asked how they hoped the data (VGI) would be used by their client; government respondents were asked to describe its actual use. All were asked to describe the app and its development, their organisation and role within, the use of $\mathrm{VGl}$, the characteristics of the volunteer, and the nature of volunteer engagement.

Respondents were selected based on their experience with the app and their leadership or managerial

Table 2. Overview of cases.

\begin{tabular}{|c|c|c|c|}
\hline & Citizen Budget & Toronto Cycling App & VanConnect \\
\hline $\begin{array}{l}\text { Best Practice } \\
\text { Example of }\end{array}$ & Citizen-centric & Consumer-centric & Hybrid \\
\hline Government & $\begin{array}{l}\text { Borough of City of Montreal, } \\
\text { Le Plateau-Mont-Royal }\end{array}$ & $\begin{array}{l}\text { City of Toronto, Cycling } \\
\text { Infrastructure and Programs- } \\
\text { Transportation Services division }\end{array}$ & $\begin{array}{l}\text { City of Vancouver, } 311 \text { Call } \\
\text { Centre }\end{array}$ \\
\hline Developer & $\begin{array}{l}\text { Open North } \\
\text { Non-profit, data host, } \\
\text { analytics }\end{array}$ & $\begin{array}{l}\text { Brisk Synergies } \\
\text { Private sector, data host, analytics }\end{array}$ & $\begin{array}{l}\text { PublicStuff } \\
\text { Private sector, data host }\end{array}$ \\
\hline Data Content & $\begin{array}{l}\text { Residents' simulated } \\
\text { budgets with postal code } \\
\text { identification, feedback }\end{array}$ & $\begin{array}{l}\text { Cyclist demographics, feedback, and } \\
\text { GPS points }\end{array}$ & $\begin{array}{l}\text { Geolocated } 311 \text { service } \\
\text { requests. feedback }\end{array}$ \\
\hline
\end{tabular}


Table 3. List of respondents.

\begin{tabular}{|c|c|c|c|c|}
\hline & Respondent \# & Sectoral Type & Organisation & Position \\
\hline \multirow{2}{*}{$\begin{array}{l}\text { Citizen } \\
\text { Budget }\end{array}$} & 1 & Government & $\begin{array}{l}\text { City of Montreal, Le Plateau- } \\
\text { Mont-Royal }\end{array}$ & Political Aide (attaché politique) \\
\hline & 2 & $\begin{array}{l}\text { Non-profit } \\
\text { developer }\end{array}$ & Open North & $\begin{array}{l}\text { Director of Product and Service } \\
\text { Development }\end{array}$ \\
\hline \multirow{2}{*}{$\begin{array}{l}\text { Toronto } \\
\text { Cycling App }\end{array}$} & $\begin{array}{l}3 \\
4\end{array}$ & Government & $\begin{array}{l}\text { City of Toronto - Cycling } \\
\text { Infrastructure and Programs }\end{array}$ & $\begin{array}{l}\text { Manager } \\
\text { Project Lead }\end{array}$ \\
\hline & 5 & $\begin{array}{l}\text { Private sector } \\
\text { developer }\end{array}$ & Brisk Synergies & CEO \\
\hline \multirow{2}{*}{ VanConnect } & $\begin{array}{l}6 \\
7\end{array}$ & Government & City of Vancouver & $\begin{array}{l}\text { Director of Digital \& Contact Centre } \\
\text { Services } \\
\text { Open Data Coordinator }\end{array}$ \\
\hline & $\begin{array}{l}8 \\
9\end{array}$ & $\begin{array}{l}\text { Private sector } \\
\text { developer }\end{array}$ & PublicStuff & $\begin{array}{l}\text { Founder, CTO of PublicStuff } \\
\text { Cloud Delivery Manager }\end{array}$ \\
\hline
\end{tabular}

position. We looked for respondents with sufficient knowledge to describe the app and the broader objectives of the project. Table 3 shows the respondent by identifying number, sectoral type, organisation, and position within the organisation. Citizen Budget interviews were conducted in person, the rest by telephone. Inperson interviewing allows for more nuance in responses on complex issues (Shuy, 2003); telephone interviews are less nuanced but are found not to sacrifice data quality or responsiveness (Siemiatycki, 1979).

We presumed that respondents might be tempted to present themselves as 'pro citizen engagement'. Respondents were not directly asked to categorise users but instead were asked multiple, semi-structured questions to triangulate responses and capture the widest possible range of perceptions of the volunteer. These included questions on motivations to develop the app, uses of the VGI, and interactions with app users. Questions on volunteer engagement were purposely open ended: "How does the app help engage citizens?" and "Are you satisfied with the level of engagement provided through the app?". This allowed respondents to express their own perceptions and, hopefully, minimise bias. We realised that use of the term 'citizen' was a potential bias, although we saw no broadly used alternative to describe a resident of the city. Respondents generally used 'citizen' without prompting.

\section{Coding}

Descriptive coding, using a mixture of a priori and invivo techniques (Saldana, 2009), was performed on the interview data. A priori codes, such as 'efficiency', and 'market' were created beforehand to classify responses as citizen- or consumer-centric. In-vivo, descriptive codes (e.g., 'dialogue', 'service coverage') were derived from the interview data and categorised with the help of a priori codes. We then grouped codes under either citizen or consumer. Assuming not all respondents would similarly interpret 'engagement', we focus on the context to which the code was applied.

\section{Results}

Results are presented in three sections. First we describe the apps, respondents, and VGI, to provide context for interview responses. Then we assess the reasons for VGI and apps. Finally, we characterise interview results in terms of respondents' perceptions of users and engagement. Results show a citizen-centric perception in all apps with some respondents described a mixture of citizen and consumer sentiment towards the apps. Respondents had different positions and emphases when it came to interpreting engagement.

\subsection{Descriptions of the App and the Role of the Respondent}

This section describes the apps and their functionality, user interface, data collection, and objectives based on interaction with the app and respondent descriptions.

Citizen Budget is our best practice example of the citizen-centric type. It is a browser-based web app that allows individuals to create their own annual budgets for Le Plateau-Mont-Royal, a borough of the City of Montreal. Users respond to questions on tax rates, levels of service (e.g., frequency of snowploughing, which is very expensive but highly important in this Northern city), and investment projects (e.g., construction of a new library). The user interface is composed of slider bars, multiple choice boxes, and binary (yes/no) switches. The budget is automatically calculated and users can be forced to balance their simulated budget. Users can implement a new tax or raise existing taxes. Citizen Budget had two main objectives: obtain citizen feedback to inform decision-making and promote civic learning by educating citizens on the cost of public services and the challenges of funding diverse urban priorities.

Figure 1 is a screenshot of the user interface. Users 
contribute their simulated budget, feedback, and a postal code, which acts as a location identifier and as a way to filter out those living outside the borough. Political aides analyse collected budget simulations and results are presented by the Mayor during annual budget consultation. App development was outsourced to Open North, a non-profit organisation promoting government transparency and public participation in Canada through online and digital tools. (Note: in the year of interviewing (2015), the app was not used due to major restructuring of the City of Montreal's budget allocation to its boroughs.)

Toronto Cycling App represents the best practice of the consumer-centric type. This smartphone-based app has two main components: a user survey and a trip collector. Users contribute demographic information and they can choose to report their satisfaction with their overall cycling experience (e.g., comfort level in traffic). Comments about satisfaction are geolocated with partial postal codes for their home and work places. Cycling trips are recorded by collecting GPS points from user phones. Users classify trips according to eight predefined categories like commute, exercise, and work. The app displays cycling-related information on a map such as road closures and bike shops. The primary objective is to collect patterns on actual cycling behaviour; route-finding specific functionality like road closures is not the primary objective of the app. A secondary objective is to assist in Toronto's cycling infrastructure planning, including their 10-year Cycling Network Plan. Figure 2 shows the cycling route data traced on a map before being uploaded, and an optional demographic survey. Brisk Synergies was the private sector developer.
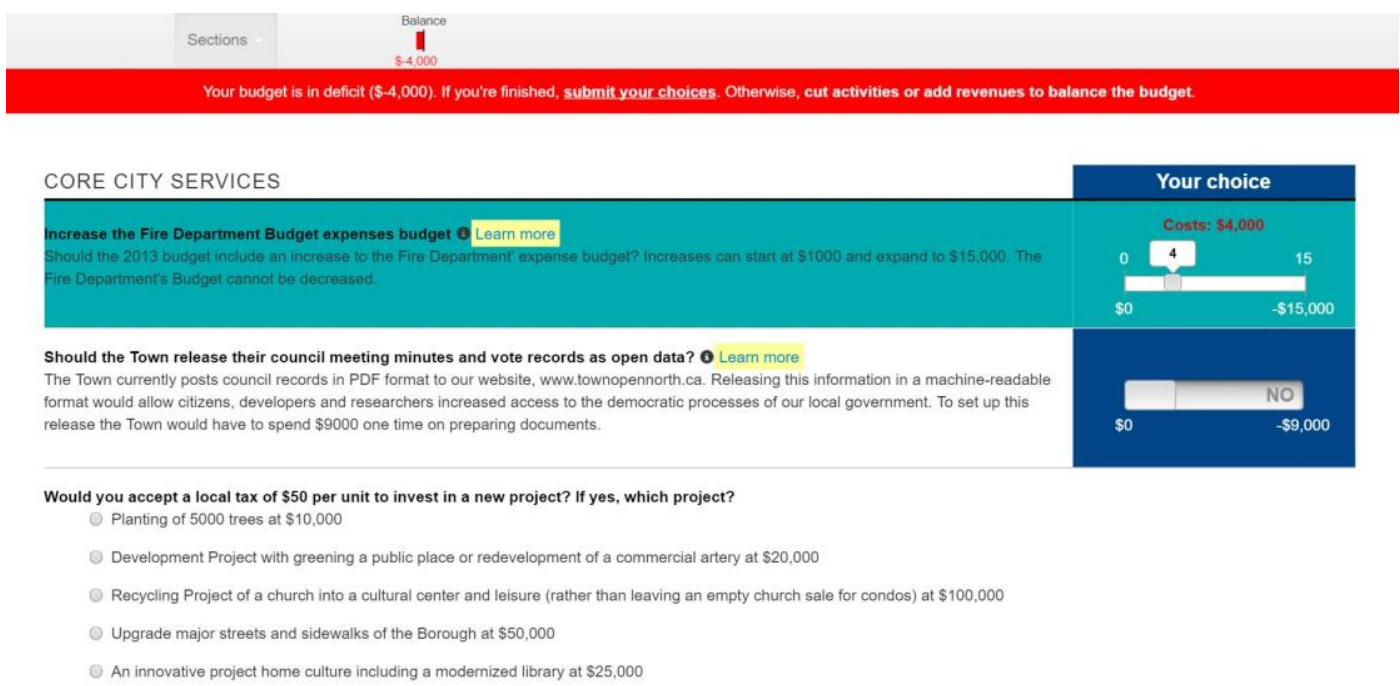

Figure 1. Citizen budget interface.

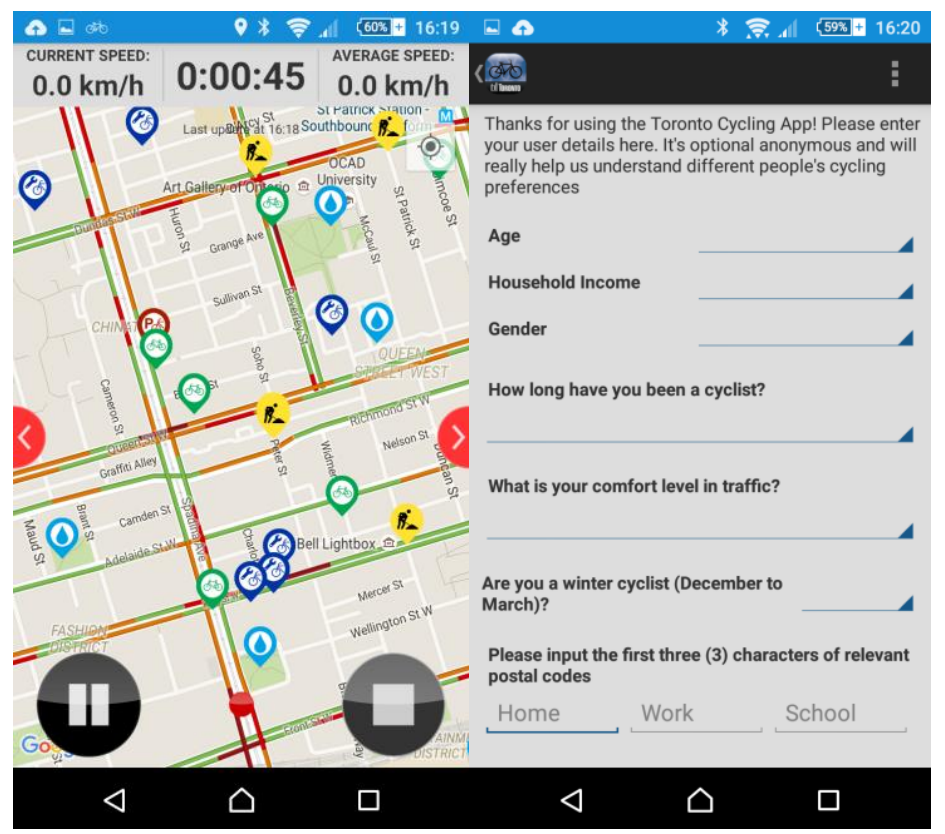

Figure 2. Toronto Cycling App interface. 
The third app, VanConnect has multiple features, but its main objective is to collect service requests for the City of Vancouver's 311 Call Centre. Major cities throughout North America and Western Europe have some form of 311-style citizen-reporting service (Gordon \& Baldwin-Philippi, 2013; Minkoff, 2016). VanConnect collects geolocated service requests that include location (coordinates and address), type (selected from a predefined list of service categories like graffiti, potholes, broken streetlights), user-generated answers to issue-specific questions (e.g. name of the object) and optional unstructured feedback. Reports are forwarded to the specific departments responsible for the identified infrastructure, or to an external organisation if outside the city's jurisdiction (e.g., Canada Post boxes). Users may receive automated updates on the status of their service request via an optional Facebook login or email registration. VanConnect displays other information, including maps and city announcements, as a separate component of the app. Figure 3 shows the predetermined list of service categories, location selection via a map interface, and options available when submitting a pothole repair request. PublicStuff was the private sector developer.

\subsection{Reason for Volunteered Data Via an App}

In this section we present respondents' reasoning for VGI as a method of engagement as well as VGI's potential to transform engagement. Reasons focused on reach, accessibility, and quality. Apps, particularly on smartphones, were seen as reaching a wider audience, particularly younger generations otherwise estranged from civic participation. Smartphones also allowed col- lection of broader types of content (e.g., images, coordinates) and at higher positional accuracy. Respondents spoke of a need or benefit to government collecting additional data. Respondent 5 reported that VGI supplied essential input to decision making and planning, providing the four main data elements needed for cycling planning, "Where are they from in the city...from and to which part city they're cycling to. And at what time". Cycling route collection via an app provides actual routes ridden by cyclists; the same exercise in public consultation might collect route preferences (Respondents 3,4$)$. Cycling planners needed data on both routes taken and demanded routes so an app was the ideal choice to map traffic separately from demand.

Respondents were asked whether VGI via apps could potentially replace traditional data collection or consultation. Respondent 1 stated that their administration had considered online-only consultation but had yet to move further. The hesitation was due to a lack of online responses. The app's population of VGI contributors (averaging 500 annually) and number of website hits (people who viewed the survey questions without contributing) outstripped the level of participation at traditional public consultations. Respondent 1 was hopeful that apps and online consultations could remedy this discrepancy. All other respondents described VGI via apps as an enhancement to, not a replacement for, traditional public consultation or feedback. Respondent 6 of VanConnect hoped the app could replace existing methods such as the 311 telephone service because of the latter's high operating costs. They believed that providing equitable service coverage was critical; therefore media such as telephone and email were still necessary to bridge any digital divides.

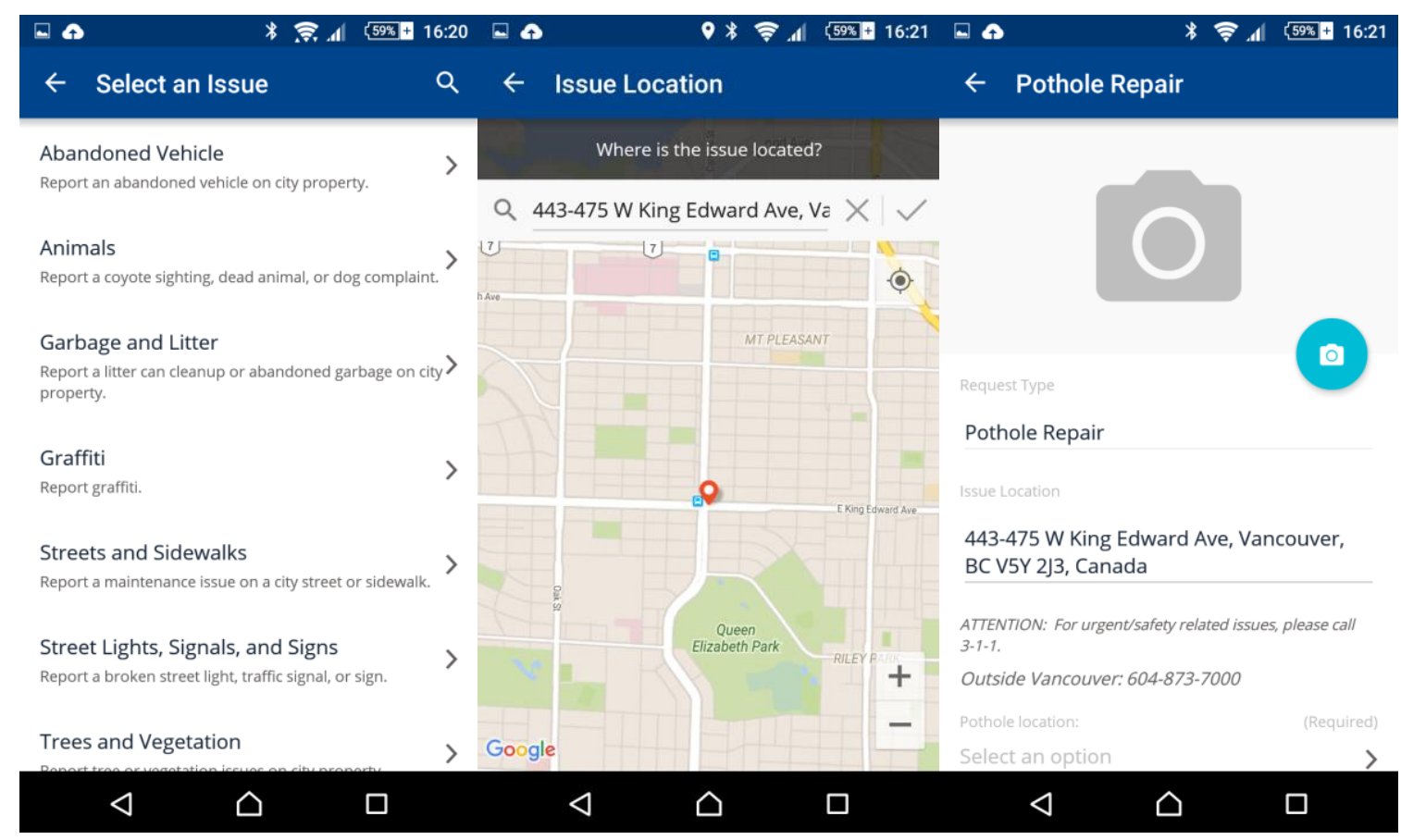

Figure 3. VanConnect interface. 


\subsection{Respondent Perceptions of App Users and Interpretations of Engagement}

This section covers respondent descriptions of and satisfaction with volunteer engagement through the app. We also asked respondents to contextualise the app within larger engagement objectives. We synthesise the results in Table 4 below.

As seen in Table 4, Citizen Budget's respondents exclusively referred to volunteers as "citizens" or "users" and contextualised them as constituents for whom government has responsibilities. Respondent 1 , the political aide, spoke of engagement as a key responsibility of "the elected", "to explain and to make it simpler for the citizen, and to be honest also". Responsibilities, they felt were invoked in the app, included citizen consultation and civic education. Respondent 2 was outspoken on citizen engagement, likely due to Open North's mission to promote citizen engagement through online tools. They differentiated between strong and weak engagement, defining engagement as ideally "to have people to have their voice heard and have a clear impact on how the budget is spent" and their non-profit being part of a "virtuous cycle" of interaction where, citizens understand that the next time "I send something, it's being heard and it's being useful".

There was disagreement on satisfaction with engagement via the app due to concern with engagement overall. Respondent 2 (Open North) was satisfied with Plateau-Mont-Royal's implementation because the surveying was run concurrently with the budget planning process. They believed VGI directly affected decision-making, which was crucial because "it's only working if people feel that what they do has an impact". Respondent 1 was somewhat dissatisfied with the level of engagement through the app. As mentioned above, the app generated a user population of 500, which far exceeded public consultations. However, this was considered insufficient in a jurisdiction of 120,000 . Nonetheless, Respondent 1 was heartened by the quality of engagement, reporting that "we are having today better discussions with the citizens than five years ago". They also attributed apps with generating higher quality political discussions at public consultations.

Toronto Cycling App respondents were generally satisfied with the quality of engagement in the app. VGI allowed users to influence the planning process instead of reacting to a completed plan. When asked about satisfaction with the level of citizen engagement via the app, they felt that "it would have been great to see engagement that was distributed around the city at a higher level. We had a lot of users that are from the downtown core, and it would have been great to see more engagement beyond that area" (Respondent 3).

Respondent 3 blurred the distinction between consumption/coproduction and certain attributes of citizenship (e.g., concerns over equity). They were "satis- fied with the way that the app can engage residents", but believed added functionality, such as service requests, would further enhance engagement into the app. At the same time, Respondent 3 reported that "we can't rely on engagement occurring in the app, at least the democratic kind." Respondent 4 expressed frustration with traditional public consultations, finding them "limiting". The app's goal was to make users "feel like they're contributing in a very useful sort of fashion. And they actually see what...what has been done...cause and effect".

Respondent 5 (Brisk Synergies) chose to interpret engagement in three ways. First, engagement represented the level of interest and participation in the cycling data initiative, which they acknowledged depended on continued marketing to sustain interest. Second, they viewed engagement as synonymous with enduser adoption. The developer believed that if users perceived the app had value then this would lead to more daily app usage, which would increase VGI contributions. Third, engagement was interpreted from a crowdsourcing perspective, where citizens provide useful information to the city to aid and, in particular, evidentially support decision-making. Matching other respondents of the consumer-centric app, coproduction was considered a form of engagement.

Our a priori-designated hybrid app, VanConnect, offered further confirmation that citizen-centric views can be framed in market-oriented language. Respondent 6 expressed three reasons for implementing the app. The first two were to enhance citizen-government interaction and to increase government efficiency. These were presented respectively as the citizen-side and business-side (i.e., front and back end) of the app. In all but two instances when "customer" was used, the respondent referred to users as "citizens". VanConnect was aimed to improve what Respondent 6 termed the "citizen experience". Citizen experience, while not explicitly defined, represented the entirety of a citizen's interaction with government and analogous to a customer experience.

The third reason for the app was to extend government efforts in collecting data and citizen requests. For Respondent 6, data collection and analysis enabled government to engage and listen to its residents. In turn, a responsive government would create an improved citizen experience. They were "pleasantly surprised" with the quality of engagement and generally satisfied with the level of engagement, but stated, "I don't know if we'll ever be 100 percent satisfied but we're certainly very happy". Respondent 6 revealed additional nuance when answering "Why did you use a mobile app?":

"We have people that use our services from two years old to 100 years old and...can we get to whole new consumer group that needs to use our pools 
COGITATIO

Table 4. Aggregated responses on citizen engagement

\begin{tabular}{|c|c|c|c|c|c|c|}
\hline $\begin{array}{l}\text { Themes around } \\
\text { engagement }\end{array}$ & City of Montreal & Open North & City of Toronto & Brisk Synergies & City of Vancouver & PublicStuff \\
\hline A priori app orientation & Citizen & Citizen & Consumer & Consumer & Both & Both \\
\hline $\begin{array}{l}\text { After analysis app orientation } \\
\text { (by respondent) }\end{array}$ & Citizen & Citizen & Both & Consumer & Both & Consumer \\
\hline $\begin{array}{l}\text { Predominant terms used to } \\
\text { refer to app users }\end{array}$ & Citizen & Citizen & User, Citizen, Resident & User & User, Customer, Citizen & User, Citizen \\
\hline $\begin{array}{l}\text { Characterizations of good } \\
\text { engagement }\end{array}$ & $\begin{array}{l}\text { Results in } \\
\text { demonstrable } \\
\text { impact on policy } \\
\text { Allows for } \\
\text { increased } \\
\text { alignment with } \\
\text { government policy } \\
\text { Improves } \\
\text { discussions in } \\
\text { traditional } \\
\text { consultations } \\
\text { Increases citizen } \\
\text { awareness of } \\
\text { political issues }\end{array}$ & $\begin{array}{l}\text { Results in } \\
\text { demonstrable impact } \\
\text { on policy } \\
\text { Enables contributions } \\
\text { to be embedded in } \\
\text { government processes } \\
\text { Creates a positive } \\
\text { feedback loop }\end{array}$ & $\begin{array}{l}\text { Improves } \\
\text { communication via ease } \\
\text { of use of app } \\
\text { Broadening of } \\
\text { geographic and } \\
\text { demographic diversity } \\
\text { User perceptions that } \\
\text { their contributions are } \\
\text { valued }\end{array}$ & $\begin{array}{l}\text { Improves } \\
\text { communication via ease } \\
\text { of use of app } \\
\text { Produces high user } \\
\text { adoption } \\
\text { Produces evidence- } \\
\text { based decision-making }\end{array}$ & $\begin{array}{l}\text { Improves } \\
\text { communication via ease } \\
\text { of use of app } \\
\text { Reduces communication } \\
\text { time between } \\
\text { contributor and } \\
\text { government } \\
\text { Enables more direct } \\
\text { interaction with } \\
\text { government } \\
\text { Generates more } \\
\text { opportunity for feedback } \\
\text { and dialogue }\end{array}$ & $\begin{array}{l}\text { Produces evidence- } \\
\text { based decision-making } \\
\text { Automates the citizen } \\
\text { to government } \\
\text { interaction } \\
\text { Enables more direct } \\
\text { interaction with } \\
\text { government }\end{array}$ \\
\hline
\end{tabular}


and community centres and our golf courses, without closing channels off that are very traditional where, more senior citizens will still want to pay in cash, they still want to come to city hall, they may be using email as opposed to a smartphone. We're...trying to open up channels; we're trying to be more efficient and more transparent and hopefully more cost effective."

Apps offered a new consumer group; market demand (for apps) needed to be met, which increased consumer choice and efficiency (through cost reduction) via the app. Complicating this purely consumer orientation was the respondent's desire to ensure equity, a citizen orientation, in 311 service provision.

Turning to the private sector, PublicStuff's Respondents 8 and 9 were outwardly citizen-centric but invoked terms related to consumption. When speaking on communication between citizen and city, both respondents spoke of frictionless communication using terms like ease, directness and automation, where "Automating the interaction and allowing for the direct lines of communication really is the core of the product" (Respondent 8). Respondents 6, 8 and 9 argued that apps provided more choices for public engagement. That interaction should be automated and cater to individual needs suggests a consumer-centric view of users.

In addition to varied definitions of engagement, where engagement was occasionally equated with mere interaction with the user interface, we found that respondents' perceptions of engagement blurred data collection with citizen engagement. For example, Respondent 8 believed that data collection would "engage their citizens and get them involved (in) submitting information (that would) help them improve the City", making the city more efficient. Conversely, data collection might matter little compared to interaction. For Respondent 2, "what people in the end put in the tool doesn't matter that much; it's what they understood from using the tool that's important". Different forms of engagement, the soft-coded citizen education and the hard-coded data collection, can occur within the same interaction. Respondent 6 saw VanConnect as "a connection piece more than just a service request app". VGI allowed them to "figure out where are the tension points in the organization, what's bothering people, and what do we need to do differently or better". Data collection represented both coproduction and a way for the city to engage residents.

\section{Discussion}

Our a priori selections of apps as consumer or citizencentric selections were not easily confirmed through interviewing. Consumer and citizen-centric characterisations overlapped and blurred distinctions. Blurring depended on the motivations for data use, the professional sector of the respondent, and the level of structuration of the contributions by endusers. We preliminarily classified Toronto Cycling App as a consumercentric app. Its government respondents viewed data collection as a discrete part of the planning process that should not sacrifice responsibilities for citizen engagement. Empirical research nuanced the citizenconsumer dichotomy. VanConnect was assumed to be a hybrid model and, while attempting to balance citizen and consumer views, responses were grounded in a business management paradigm. Only Citizen Budget aligned with a citizen-centric orientation.

Classification challenges partially stem from numerous functionalities implemented in the same app, which in turn lead to diverse user roles and potential for produsage. Respondent 6 labelled their app an "omni channel approach to how we deliver customer service to citizens". This multi-faceted app obscures the distinctions between types of users, rendering it difficult to pinpoint whether engagement or participation serves citizens or consumers. Just as multiple functions converge into a single app, we argue that usage will move beyond simple data production or consumption, to produsage (and conceivably its citizen analogue of rights and responsibilities). VanConnect's combination of VGI collection and tailored data output such as maps and announcements means a user can contribute and receive content. Engagement prospects of VGI apps will depend on the context in which data is processed and objectives are articulated.

We found apps being deployed to increase accessibility of government and reach out to the previously unengaged. However, accessibility may be interpreted as an instrument to capture (free) untapped labour, reflecting concerns over market framings that sway governance in a participatory democracy (Aberbach \& Christensen, 2005). Apps ostensibly increase choice but developers leave the responsibility to participate with the user. Presumably, increased availability of communication channels will spur engagement with those, for example, with a preference for mobile technology. Just because anyone can use the app then it might be concluded that everyone is using it (Elwood \& Lesczynski, 2013). Citizen Budget's insufficient user population suggests that apps alone cannot generate that connection. This supply-side-“build the app and they will engage"-approach addresses demands for digitallyenabled efficiency but may fail to inculcate civic duty or overcome digital divides in participation.

Considerations of engagement vary among and within apps, including user adoption, levels of interaction with the user interface, data collection, and degrees of empowerment. A single interaction can simultaneously represent several levels of engagement (e.g., direct conversation, participation within a planning process). An interaction can be perceived hierarchical- 
ly, as a gateway to more meaningful forms, although respondents may not agree on the order. Brisk Synergies' response contrasts with the virtuous cycle of engagement described by OpenNorth. Instead of increased contributions being driven by demonstrable impacts from engagement, the Brisk Synergies respondent suggested an app's utility to volunteers will drive contributions. We note that a virtuous cycle of engagement does not dictate users of Citizen Budget also be contributors. Users may first gain knowledge of the budget, for example by visiting the website; they may or may not submit contributions at subsequent rounds of consultation. Using an app does not necessitate contribution and engagement can be website visits. We argue that planners should reach agreements on definitions and goals of forms of engagement. Moreover, there may be a design-reality gap (Paré, 2015) from intended to actual engagement. Government may expect strong engagement to occur simply by providing consumer-friendly interfaces, but the outcome may be much weaker than anticipated.

Lastly, our research points toward a data-driven government, in which more data is considered better and VGI is sought to confirm existing policy. Politics-asusual represents a chronic governance problem but may be exacerbated with the use of VGI. Toronto Cycling App respondents asserted that more data always would improve decisions, without clear ideas of how the big data would be managed. Politicians may seek to use data and statistics to support pre-existing policy outcomes. VGI from Citizen Budget allowed the Mayor to justify budgeting decisions and demonstrate the administration's alignment with their constituency. Respondent 1 admitted that the VGI had yet to contradict government plans. VGI may as easily be co-opted by political agendas as used to inform policies. Moreover, we note potential issues in the aggregation of VGI. If citizens are presented with aggregated results after the budget is complete, they must trust that the VGI was appropriately analysed and their contributions influences the final decisions. Respondent 1 also revealed a lack of analytical sophistication. Simple percentage calculations, with no tests for significance, appeared sufficient even though there was ample opportunity to conduct deeper descriptive statistics. By not taking advantage of explorations afforded by the data, governments may fail in their integration of VGI into decisionmaking and instead create another layer of opacity.

\section{Conclusion}

Our research was prompted by Massey's (2013) concern over creeping vocabulary of neoliberalism. Market-based terms, like individual self-interest, normalise what she saw as an inevitability of social inequality through capitalism and ignore non-monetary transactions and social responsibilities that are necessary in the social life of the city. Forcing a citizen into a customer role can transactionalise their relationship with government, eventually producing a hegemony of the market that displaces politics and democracy. This potential erosion did not begin with apps, but might be nurtured by the appification of contributions from inhabitants of the city, who are increasingly easy to characterise as producers contributing to more efficient service delivery than as citizens engaged in a messy democracy.

VGI as used within government may inevitably trend towards a consumer-orientation. The appification of VGI allows government to control whether VGI offers a form of citizen engagement or a platform for the coproduction of public services. If the latter, citizens must turn back towards traditional methods of consultation to have their voices heard. Appification of government services, in these cases, does not appear to be leading to a redistribution of power. Government does not appear to bend to what the literature argues is VGI's empowerment potential, namely the unstructured, heterogeneous characteristics of the data (Zook, Graham, Shelton, \& Gorman, 2010). Instead of embracing the crowd and realising the empowerment promised by data heterogeneity, government may fit VGI to its own processes and infrastructure without seeking radical modifications, allowing control over data to remain in squarely within the government domain. Our findings suggest that the empowerment opportunities of VGI might be high in theory (Elwood, 2008; Elwood \& Leszczynski, 2013), but low in practice.

A limitation of our study was that it did not extend to perspective of endusers - the city residents. Capturing the perspective of contributors would allow us to assess whether they think of themselves as citizens or clients and allow for a comparison between government, developer, and citizen perspectives. A mismatch in perspectives could indicate that government VGI endeavours are creating false expectations and therefore a failure in their app-enabled citizen engagement strategies.

Should VGI apps replace traditional modes of civic participation, as hinted by respondents, and app outsourcing continue through consumer-oriented developers, we may see a flowering of NPM-like governance that will fundamentally alter roles and expectations. Use of market terminology is only likely to increase with government's appification of VGI. We look forward to research that attempts to reconcile market terminology with citizen participation vis-a-vis the state.

\section{Acknowledgments}

This research was funded in part by the Canadian Social Science and Humanities Council Partnership Grant 8952012-1023. We would like to thank the grant's research partners in helping coordinate research interviews. 


\section{Conflict of Interests}

Respondents 2 and 7 are partners in the grant but were not obligated to participate.

\section{References}

Aberbach, J. D., \& Christensen, T. (2005). Citizens and consumers. Public Management Review, 7(2), 225246.

Adams, D. (2013). Volunteered geographic information: Potential implications for participatory planning. Planning Practice and Research, 28(4), 464-469.

Baykurt, B. (2012). Redefining citizenship and civic engagement: Political values embodied in FixMyStreet.com. In Proceedings. of the 12th annual conference of the Association of Internet Researchers (AolR'11). Seattle, WA: AolR

Bovaird, T. (2007). Beyond engagement and participation: User and community coproduction of public services. Public Administration Review, 67(5), 846860.

Bruns, A. (2007). Produsage, generation C, and their effects on the democratic process. In Media in Transition 5. Boston, MA: MIT.

Bruns, A. (2008). Blogs, Wikipedia, Second Life, and beyond: From production to produsage In Digital Formations (Vol. 45). New York: Peter Lang.

Budhathoki, N. R., Bruce, B., \& Nedovic-Budic, Z. (2008). Reconceptualizing the role of the user of spatial data infrastructure. GeoJournal, 72(3-4), 149-160.

Carl, T. (2012, May 7). The G4: Setting city data free. Canadian Government Executive. Retrieved from http://canadiangovernmentexecutive.ca/the-g4setting-city-data-free

Coleman, D. J. (2013). Potential contributions and challenges of VGI for conventional topographic basemapping programs. In D. Sui, S. Elwood, \& M. Goodchild (Eds.), Crowdsourcing geographic knowledge (pp. 245-263). Netherlands: Springer.

Coleman, D. J., Georgiadou, Y., \& Labonte, J. (2009). Volunteered geographic information: The nature and motivation of produsers. International Journal of Spatial Data Infrastructures Research, 4(1), 332-358.

Denhardt, R. B., \& Denhardt, J. V. (2000). The new public service: Serving rather than steering. Public Administration Review, 60(6), 549-559.

Elwood, S. (2008). Volunteered geographic information: Future research directions motivated by critical, participatory, and feminist GIS. GeoJournal, 72(3-4), 173-183.

Elwood, S., \& Leszczynski, A. (2013). New spatial media, new knowledge politics. Transactions of the Institute of British Geographers, 38(4), 544-559.

Fast, V., \& Rinner, C. (2014). A systems perspective on volunteered geographic information. ISPRS International Journal of Geo-Information, 3(4), 1278-1292.
Ganapati, S. (2011). Uses of public participation geographic information systems applications in egovernment. Public Administration Review, 71(3), 425-434.

Ghose, R. (2005). The complexities of citizen participation through collaborative governance. Space and Polity, 9(1), 61-75.

Goodchild, M. F. (2007a). Citizens as sensors: The world of volunteered geography. GeoJournal, 69(4), 211221.

Goodchild, M. F. (2007b). Citizens as voluntary sensors: Spatial data infrastructure in the world of Web 2.0. International Journal of Spatial Data Infrastructures Research, 2, 24-32.

Goodchild, M. F. \& Glennon, A. (2010). Crowdsourcing geographic information for disaster response: a research frontier. International Journal of Digital Earth, 3(3), 231-241.

Gordon, E., \& Baldwin-Philippi, J. (2013). Making a habit out of engagement: How the culture of open data is reframing civic life. In B. Goldstein \& L. Dyson (Eds.), Beyond transparency: Open data and the future of civic innovation (pp. 139-149). San Francisco, SF: Code for America Press.

Haklay, M., Antoniou, V., Basiouka, S., Soden, R., \& Mooney, P. (2014). Crowdsourced geographic information use in government. London: Global Facility for Disaster Reduction and Recovery (World Bank).

Harris, T., \& Weiner, D. (1998). Empowerment, marginalization, and "community-integrated" GIS. New Zealand Cartography and Geographic Information Systems: The Journal of the New Zealand Cartographic Society, 25(2), 67-76.

Harvey, D. (2005). A brief history of neoliberalism. Oxford, UK: Oxford University Press.

Hecht, B., \& Stephens, M. (2014). A tale of cities: Urban biases in volunteered geographic information. In International AAAl Conference on Web and Social Media (pp. 197-205). Ann Arbor, MI: University of Michigan.

Hood, C. (1995). The "new public management" in the 1980s: Variations on a theme. Accounting, Organizations and Society, 20(2-3), 93-109.

Johnson, P., \& Sieber, R. (2011). Motivations driving government adoption of the Geoweb. GeoJournal, 77(5), 667-680.

Johnson, P., \& Sieber, R. (2013). Situating the adoption of VGI by government. In Crowdsourcing Geographic Knowledge (pp. 65-81). Netherlands: Springer.

King, S. F., \& Brown, P. (2007). Fix My Street or else: Using the internet to voice local public service concerns. In Proceedings of the 1st International Conference on Theory and Practice of Electronic Governance (pp. 72-80). New York: ACM.

Leszczynski, A. (2012). Situating the geoweb in political economy. Progress in Human Geography, 36(1), 7289. 
Massey, D. (2013). Vocabularies of the economy. Soundings: A Journal of Politics and Culture, 54(1), 9-22.

Minkoff, S. L. (2016). NYC 311: A tract-level analysis of citizen-government contacting in New York City. Urban Affairs Review, 52(2), 211-246.

Mooney, P., Sun, H., \& Yan, L. (2011). VGI as a dynamically updating data source in location-based services in urban environments. In Proceedings of the 2nd international workshop on Ubiquitous crowdsourcing UbiCrowd'11 (p. 13). New York: ACM Press.

Nam, T. (2012). Suggesting frameworks of citizensourcing via Government 2.0. Government Information Quarterly, 29(1), 12-20.

Ostrom, E. (1996). Crossing the great divide: Coproduction, synergy, and development. World Development, 24(6), 1073-1087.

Paré, D. (2015). Enhanced democracy? Really? Assessing design-reality gaps in Canadian municipal-level open government platforms. Paper presented at Union for Democratic Communications: Circuits of Struggle, Toronto, Canada.

Roche, S., \& Rajabifard, A. (2012). Sensing places' life to make city smarter. In Proceedings of the ACM SIGKDD International Workshop on Urban Computing-UrbComp'12 (p. 41). New York: ACM Press.

Saldana, J. (2009). The Coding Manual for Qualitative Researchers (3rd ed.). Thousand Oaks, CA: Sage.

Sandoval-Almazan, R., Gil-Garcia, J. R., Luna-Reyes, L. F., Luna, D. E., \& Rojas-Romero, Y. (2012). Open government 2.0: Citizen empowerment through open data, web and mobile apps. In Proceedings of the 6th International Conference on Theory and Practice of
Electronic Governance-ICEGOV '12 (p. 30). New York: ACM Press.

Seeger, C. J. (2008). The role of facilitated volunteered geographic information in the landscape planning and site design process. GeoJournal, 72(3-4), 199213.

Shuy, R. W. (2003). In-person versus telephone interviewing. In J. Holstein \& J. F. Gubrium (Eds.), Inside interviewing: New lenses, new concerns (pp. 175193). Thousand Oaks, CA: Sage.

Sieber, R., \& Haklay, M. (2015). The epistemology(s) of volunteered geographic information: A critique. Geo: Geography and Environment, 2(2), 122-136.

Sieber, R., Robinson, P., Johnson, P., \& Corbett, J. (2016). Doing public participation on the geospatial web. Annals of the American Association of Geographers. doi:10.1080/24694452.2016.1191325

Siemiatycki, J. (1979). A comparison of mail, telephone, and home interview strategies for household health surveys. American Journal of Public Health, 69(3), 238-245.

Stephens, M. (2013). Gender and the geoweb: Divisions in the production of user-generated cartographic information. GeoJournal, 78(6), 1-16.

Tulloch, D. L. (2008). Is VGI participation? From vernal pools to video games. GeoJournal, 72(3-4), 161-171.

Zook, M., Graham, M., Shelton, T., \& Gorman, S. (2010). Volunteered geographic information and crowdsourcing disaster relief: A case study of the Haitian earthquake. World Medical \& Health Policy, 2(2), 6-32.

\section{About the Authors}

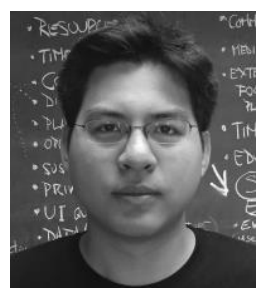

Suthee Sangiambut is a graduate student at McGill University's Department of Geography. His research is related to open government, open data, and civic apps, in particular their impacts on citizen-government interactions, government practices, and policy.

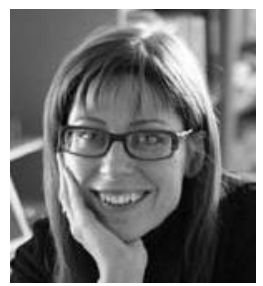

Renee Sieber is an Associate Professor in the Department of Geography. Her interests lay in the use and value of information technology by marginalized communities, community based organizations, and social movement groups; public participation GIS/participatory GIS/participatory Geoweb; use of GIS in the environmental movement; development of e-commerce tools for use in marginalized communities. 